\title{
Héctor Samour
}

\section{Aspectos ideológicos del paradigma neoliberal}

El renacimiento del pensamiento liberal, en su forma de neoliberalismo, surge al menos desde la década de los años ochenta: Reagan, Thatcher y Kohl, los programas y las políticas económicas impuestas por el Banco Mundial y el Fondo Monetario internacional, al menos desde la década de los años ochenta, e incluso mucho antes, el trabajo de los "Chicago Boys" y su aplicación en una serie de países, en particular en América Latina, dan muestra de que el pensamiento neoliberal ya tiene una cierta tradición en nuestro continente. Su resurgimiento y predominio ha coincidido con el agotamiento de la teoría social demócrata y el naufragio del socialismo real y revolucionario. El neoliberalismo se ha proclamado la ideología triunfante y hegemónica, toda vez que la apertura del comercio, la liberalización del mercado, la privatización, la descentralización y la reducción del Estado se han convertido en los principios rectores de la política económica de la mayor parte de los gobiemos del mundo.

Desde esta perspectiva, en lo que sigue se enfatizarán las principales tesis del pensamiento neoliberal. Como se verá, el neoliberalismo no es sólo un conjunto de políticas de ajuste o una mera forma de organizar la economía, sino una ideología cuyo paradigma comprende una concepción de las ciencias sociales, una antropología, una teoría de la sociedad y una teoría de la política, y que se presenta con pretensiones cognoscitivas universales y reduccionistas.

Como ideología, el neoliberalismo contemporáneo tiene diferencias esenciales con el liberalismo clásico. Para Luis de Sebastián, el neoliberalismo es la negación del liberalismo clásico, por cuanto implica un darwinismo social opuesto a los ideales, motivaciones y objetivos económicos y sociales de los autores de la economia política británica, como Adam Smith, Malthus o Stuart Mill. El liberalismo de estos pensadores tenía un ideal competitivo humanista congruente con los ideales revolucionarios de la burguesía ascendente y con una concepción ética que se expresaba en la preocupación de los economistas clásicos por la suerte de las gentes o el problema social, que la revolución industrial estaba generando. En América Latina, este liberalismo tuvo un fuerte componente nacio- 
nalisla e, incluso, antiimperialista (Bedoy, 1993). Para Franz Hinkelammert (1984), el pensamiento neoliberal se distingue del pensamiento liberal original. Si bien ambos son pensamientos de legitimación de la sociedad burguesa, ambos difieren en el tipo de sociedad burguesa que legitiman y en las sociedades contra las que se dirigen. El pensamiento liberal clásico es un discurso de legitimación đe la sociedad burguesa dirigido contra las sociedades precapitalistas. El pensamiento neoliberal legitima la sociedad burguesa contra las tendencias hacia una sociedad socialista. Es una legitimación del capitalismo y, a la vez, una deslegitimación de la sociedad socialista. El pensamiento liberal original se presentaba como una superación de todas las sociedades anteriores al capitalismo. El neoliberalismo contemporáneo es un pensamiento que busca evitar la superación de la sociedad burguesa por la sociedad socialista.

Por otra parte, la identificación de "liberalismo" sin más con "neoliberalismo" es inadecuada porque el neoliberalismo es sólo una de las corrientes del liberalismo contemporáneo, muy diferente del liberalismo democrático de John Dewey, Harold Laski, Crawford Macpherson, Ralf Dahrendorf, Norberto Bobbio, Raymon Aron y John Rawls (Merquior, 1993). Hay estudios que destacan con rigurosidad la génesis y el desarrollo del liberalismo en sus diferentes versiones, tanto progresistas como conservadoras, resaltando con nitidez los rasgos que los diferencian. No es lo mismo el "liberalismo" de Popper, Mises y Hayek, que el liberalismo de "izquierda" de Dewey, Keynes o Kelsen; o el liberalismo "sociológico" de Aron y Dahrendorf y el neocontractualismo de Rawls y Bobbio (ibidem).

\section{El paradigma neoliberal y su crítica}

Podemos hablar de un paradigma neoliberal. Los paradigmas en las ciencias sociales difieren enormemente de los de las ciencias naturales analizados por Thomas Kuhn (cfr., 1971). Su característica más sobresaliente es su amplitud temática, que generalmente contiene una concepción de la ciencia, una antropología, una teoría de la sociedad, una teoría de la política y del Estado. Si bien esto puede ser una objeción a la teoría social por su dificultad para delimitar su objeto, a diferencia de las ciencias naturales, sin embargo, hay que tener en cuenta que en el ámbito social los fenómenos se entrelazan y forman una totalidad en sentido estricto, por lo que el análisis de un grupo de fenómenos no se puede realizar sin la referencia a los demás (Hinkelammert, 1977; Ellacuría, 1991). Además, los paradigmas en las Ciencias Sociales son sucesivos y coexistentes, por lo que no hay "ciencia normal" con un solo paradigma que determine la investigación. Otro de los rasgos es que sus principios no están claramente explicitados ni expuestos separadamente de las teorías y concepciones de los autores de las corrientes que se inscriben en él. Incluso, muchos de ellos tienen el carácter de supuestos que no aparecen en el primer plano del discurso. Pero se trata de principios o hipótesis teóricas cuestionables, y la crítica a un paradigma 
se vuelve radical cuando el cuestionamiento no sólo se refiere a algunos de sus principios y leorías, sino a su estructura teórica y a su paradigma.

A continuación expondré críticamente algunas proposiciones teóricas centrales o principios del paradigma neoliberal. En primer lugar me referiré a su antropología, en según lugar a su teoría de la sociedad y, finalmente, a su teoría de la política.

\section{La antropología neoliberal}

No existe en el neoliberalismo una antropología sistematizada y elaborada en forma coherente, y muchas de sus proposiciones teóricas son descripciones fácticas de la realidad humana tal y como ésta se ha configurado históricamente dentro del sistema capitalista en sus diferentes fases históricas. El neoliberalismo pretende, tal y como en su tiempo lo intentó el liberalismo clásico, fundar su concepción de la sociedad y del Estado en una antropología. Sin embargo, como muestra Macpherson (1970) en el caso de Hobbes y Locke, no logra evitar la circularidad, pues conforma su visión del ser humano extrapolándola de las relaciones sociales existentes. Es decir, un conceplo de ser humano, extraído de un modelo histórico de sociedad, es hipostasiado y presentado como el paradigma universal de lo humano.

Asentado eso, el modelo antropológico neoliberal se reduce a los siguientes principios:

1. El individualismo posesivo (Macpherson) que eleva la propiedad privada a propiedad esencial de la naturaleza humana. El ser humano es libre y esta libertad reside en el hecho de que cada individuo es propietario de sí mismo y de sus bienes. La propiedad y, por ende, la libertad son evidencia de la naturaleza y no hace falta demostrarla ni justificarla; es una verdad universal. Desde esta perspectiva, el ser humano se define, en última instancia, por su cualidad poseedora que lo determina como un sujeto de preferencias y gustos llamado a realizar su esencia como competidor en el mercado. Es una concepción del ser humano radicalmente economicista que proviene del liberalismo clásico de Hobbes, Locke y Smith, y que es asumida por los autores neoliberales. Entre las críticas más importantes se destacan las que provienen del liberalismo democrático de John Stuart Mill, Harold Laski y Crawford Macpherson. Hinkelammert señala que se trata de una concepción que hace abstracción del ser humano como un ser de necesidades y lo convierte en un puro sujeto de preferencias, así reduce la racionalidad económica a un mero problema de equilibrio de factores y de precios relativos, soslayando el problema de la satisfacción de las necesidades básicas y el del equilibrio ecológico, esto es, el de las relaciones entre el ser humano y la naturaleza (1977 y 1984). Se trata de la exaltación de un "homo economicus", sin trabas, que establece sus relaciones sociales literalmente de individuo a individuo, con el mínimo de reglas, sólo las necesarias para poder mantener su capacidad de hacer lo que quiera sin dañar a nadie (López Camps, 1993). 
2. El ser humano es básicamente un ser de normas y de tradiciones. Es una tesis que Popper sostiene como uno de los principales principios liberales. Las instituciones solas nunca son suficientes si no están atemperadas por las tradiciones. Las instituciones son siempre ambivalentes, en el sentido de que, en ausencia de una tradición fuerte, lambién pueden servir al propósito opuesto para el que estaban destinadas a servir. En este principio se basa la "ingeniería fragmentaria" de Popper, que no pretende revolucionar la sociedad sino únicamente reformarla sobre la base de un respeto a la más importante de las tradiciones que es el "marco moral". Esta sobrevaloración del papel de las normas y tradiciones en la vida social proviene de un supuesto conservador: que ellas son racionales por el sólo hecho de existir, por cuanto representan la sabiduría de las generaciones anteriores. Este supuesto pretende sustraer las tradiciones del análisis racional y soslaya que con frecuencia las normas y el "marco moral" de una sociedad son expresión de la cultura dominante e interiorización de relaciones de poder y que, por tanto, más que constituir el marco adecuado para el despliegue de la libertad humana, son un obstáculo para la misma.

3. Los seres humanos son naturalmente desiguales y sólo puede haber igualdad ante el mercado y ante la ley. El concepto de "igualdad de oportunidades" significa en el neoliberalismo, no un derecho igual a una vida plenamente humana para todos, sino "el mismo derecho, igual para todos, de participar en la carrera competitiva para alcanzar el máximo beneficio posible" (Macpherson, 1968, p. 64). Con este supuesto se justifica la desigualdad de la propiedad porque la raíz de la misma no está en el tipo de división social del trabajo o en las relaciones sociales de producción, sino en la desigualdad de fuerza y destreza, en el diferente mérito personal de cada uno en la lucha competitiva para conseguir bienes. $O$ en otras palabras, el binomio opulenciapobreza no es un problema estructural de las relaciones sociales capitalistas, sino un problema de ingenio personal y de mayor o menor aplicación en la competencia del mercado. Las desigualdades sociales son consecuencia únicamente de las desigualdades naturales. Desde esta perspectiva, el neoliberalismo es un darwinismo social que interpreta el aumento del número de pobres como un costo necesario de la evolución social, para que los mejor dotados prosperen y los menos dotados desaparezcan.

4. La libertad es individual, negativa y sólo económica. Se excluye la dimensión positiva de la libertad, como capacidad efectiva de hacer y autorrealizarse. Los filósofos políticos distinguen con frecuencia un concepto liberal clásico de libertad del concepto democrático de libertad. En la visión puramente liberal, libertad significa sólo ausencia de coerción. En el concepto democrático, libertad significa fundamentalmente capacidad de autodeterminación (Merquior, 1993, p. 23). En el primer concepto quedan comprendidas las llamadas libertades negativas que siempre son libertades contra la posible interferencia de alguien. Aquí se inscriben las libertades civiles, la libertad de expresión y la libertad de 
mercado. La libertad posiriva es, por el contrario, el deseo de autodeterminarse en forma autónoma. No es libertad meramente contra, sino libertad para, es decir, para el autodominio y el control de la propia vida. La teoría y defensa de libertad que realiza el neoliberalismo se reduce sólo a la dimensión negativa de la libertad como ausencia de coerción, haciendo abstracción de sus dimensiones filosóficas, psicológicas, sociales, políticas y culturales, para exaltar su dimensión de libertad económica en y para el mercado. El único marco de realización es el mercado. Esto responde a su visión del ser humano como propietario, y de la sociedad como mundo de propietarios que se encuentran y reconocen a través del intercambio de mercancías y donde realizan su libertad (Samour, 1987; Mairet, 1980).

5. El neoliberalismo en cuanto exige la sumisión de los individuos al mercado y sus leyes, cae en un individualismo autocontradictorio (Hinkelammert, 1984, p. 77). Es un individualismo que niega al individuo su razón subjetiva e individual, y la sustituye por la razón emanada del mecanismo colectivo de producción de decisiones determinados por el mecanismo del mercado, al cual todos deben someterse. Esto repercute en la visión liberal de la libertad humana: "el hombre es libre en tanto y en cuanto los precios son libres" (Hinkelammer1). La liberación del ser humano es consecuencia y también subproducto de la liberación de los precios. Haciendo libres los precios, el ser humano se libera. Esta visión de la libertad contrasta con la visión que tiene toda la tradición del pensamiento crítico. Della volpe (1969) distingue entre libertad socialista y libertad burguesa. La libertad burguesa es la libertad civil, esto es, la libertad de los miembros de la sociedad civil en su sentido histórico y técnico: la libertad de los productores capitalistas, garantizada políticamente por la separación de poderes $y$, específicamente, por el poder legislativo-representativo. La libertad socialista, en cambio, es una libertad igualitaria y expresa el derecho de cualquier ser humano al reconocimiento social de sus cualidades y capacidades personales. Es la instancia democrática, realmente universal, del mérito, es decir, de la potenciación social del individuo y, por lo tanto, de su personalidad. Es una libertad en función de la justicia. En una línea similar, Ellacuría (1990) definió la libertad humana como autodeterminación de lo que el ser humano quiere ser y de lo que quieres hacer en función de lo que quiere ser, cualesquiera que sean los estímulos o tendencias que acompañen este querer. "La libertad es, por tanto, "libertad de" la naturaleza, pero "en" y "desde" la naturaleza como subtensión dinámica y, sobre todo, libertad "para ser lo que quiere ser"(ibidem, p. 350). La libertad no es sólo "de", no es sólo negativa, sino también es libertad "para" realizarse humanamente, a partir de los condicionamientos que nos impone nuestra circunstancia. Desde esta perspectiva, Ellacuría critica el concepto liberal de libertad como unilateral y fundado en la propiedad privada y la riqueza y propone un concepto integral de libertad referido a los pobres y la pobreza y que se concretiza $\longrightarrow$ debe concretizarse- como un proceso de liberación. "La 
liberalización - dice Ellacuría - parece que tiene como objetivo la libertad, pero pretende hacerla por camino falso, donde la libertad de unos pocos se identifica con la negación real de la misma para los demás", y donde se supone " que sólo el tener-más con referencia a tener-más-que-otros, es lo que posibilita el ser-más, el ser realmente libre" (Ellacuría, 1985, pp. 101-102). El objetivo primario de la liberación es, en cambio, la justicia, "entendiendo por justicia que cada uno sea, tenga y se le dé, no lo que se supone que ya es suyo porque lo posee, sino lo que le es debido por su condición de persona humana y de socio de una determinada comunidad y, en definitiva, miembro de la misma especie" (ibidem).

\section{Visión neoliberal de la sociedad y la política}

Podemos caracterizar esta visión a partir de los siguientes principios:

1. La historia no tiene un sentido o un fin determinado, pero consiste en el desarrollo y la lucha entre la sociedad abierta y cerrada (Popper, 1973): "La historia no tiene orden, lógica, sentido y mucho menos una dirección racional que los sociólogos, economistas o ideólogos podrían detectar por anticipado... ¿Qué es, entonces, la historia? Una improvisación múltiple y constante, un animado caos al que los historiadores dan apariencia de orden, una casi infinita multiplicación contradictoria de sucesos que - para poder entenderlos - las ciencias sociales reducen a arbitrarios esquemas y a síntesis y derroteros que resultan en todos los casos una ínfima versión e incluso caricatura de la historia real" (Vargas Llosa, 1992, p. 6).

Si bien se puede estar de acuerdo con Popper en la importancia de los sentidos subjelivos y de las acciones personales en la historia, así como en la falta de existencia de un fin predeterminado en ella, sin embargo, los acontecimientos históricos muestran tendencias y sentidos objetivos que no pueden reducirse a las puras significaciones e intenciones de los sujetos. Además, la historia tiene un carácter procesual y estructural por el que los acontecimientos históricos nunca son unidades aislables, sino momentos de un proceso en virtud del cual unos acontecimientos vienen incluidos o están vinculados a otros (Ellacuría, 1990). Por ello la explicación histórica no puede reducirse a puros comportamientos individuales y subjetivos.

Además, la distinción entre sociedades cerradas y abiertas es esquemática e ideologizada, criticable en su valor científico y más bien es una caracterización dirigida a descalificar el socialismo y a cualquier movimiento que pretenda la superación de la sociedad capitalista, a la que los neoliberales consideran -mistificadamente - una sociedad abierta por antonomasia.

2. La sociedad capitalista contemporánea es la mejor de cuantas han existido $y$ es insuperable. Se apela a los hechos históricos y, en concreto, al derrumbe del 
"socialismo real" para proclamar las bondades y supremacía del capitalismo sobre cualquier tipo de sociedad. En este sentido, el neoliberalismo proclama el agotamiento de las utopías y el advenimiento del "final de la historia". El neoliberalismo sostiene que el descalabro del socialismo representa, no únicamente el fracaso de una opción económica, sino el fin de un mito y de sus valores asociados, especialmente de aquellos que vinculan la lucha social con el progreso histórico y sustentan la superioridad del socialismo sobre el capitalismo. A partir de aquí, el neoliberalismo sostiene dos cosas:

(a) La imposibilidad de diseñar proyectos emancipadores alternativos al capitalismo. Se afirma que el movimiento de la historia, en sentido hegeliano, se ha acabado por la desaparición de la negación, y hemos llegado, por tanto, al final de la historia $y$ al futuro definitivo por la hegemonía incuestionable de la ideología neoliberal y del sistema capitalista, sin otra altemativa que sea capaz de convertirse en su antítesis (Fukuyama, 1989).

(b) La inutilidad de las formas ideológicas y de las utopías. No existen referentes únicos ni puede haberlos. Lo único que cuenta es la acción inmediata. Esto apunta al "fin del socialismo" y su propuesta de una sociedad sin explotación. Los individuos y grupos sociales pueden orientar su acción a través de una pluralidad de sentidos, aunque siempre dentro de los parámetros del liberalismo (Femández, 1993; López Camps, 1993). Los autores neoliberales no han podido elaborar una argumentación válida y enuncian una serie de tesis que son insuficientes $\mathrm{e}$ infundadas.

Para sostener el carácter insuperable del capitalismo, apelan a que es el sistema más acorde con la naturaleza humana y que, por tanto, cambiarlo supone cambiar al ser humano, lo cual es imposible. Popper deriva el carácter insuperable del capitalismo postulando una especie de ley de tendencia que dice que el intento de los revolucionarios de crear una nueva sociedad conduciría al retomo de la animalidad, y de allí recomenzaría el proceso de la evolución humana que desembocaría en un nuevo período capitalista, de allí a otra revolución que llevaría a otro retomo a la animalidad y así sucesivamente (Vergara, 1984). Todo intento de "realizar el cielo en la tierra, nos seduce a transformar la tierra en un infiemo; un infiemo, como solamente lo pueden realizar unos hombres contra otros" (Popper, citado por Hinkelammert, 1984, p. 168). Su postura antiutópica lleva a una hipóstasis del capitalismo actual como el límite de la posibilidad de toda historia. En general, el anti-utopismo militante de los teóricos neoliberales repudia el socialismo como utopía y creen que su anti-ulopismo es de por sí garantía de factibilidad, pero no visualizan el carácter utópico del proyecto liberal.

Apoyándose en estudios de Polanyi, Lechner (1981) señala que el surgimiento del capitalismo no obedeció a ninguna necesidad histórica o a una tendencia inscrita en la naturaleza humana. Fue producto de la confluencia de una serie de 
factores económicos, sociales, políticos, jurídicos y culturales. Por tanto, no se puede sostener su carácter insuperable apoyándose en su supuesta correspondencia con la naturaleza humana o el orden natural. En la actualidad, el capitalismo enfrenta una crisis ecológica, de desempleo, de pauperización cuya solución desborda los límites de la sociedad capitalista. Se trata de la actualidad de la crítica de Marx al capitalismo, mediante la cual éste denuncia al mercado capitalista como un automatismo mortal que subvierte las propias fuentes de la productividad sobre la cual fundamenta su eficacia: el hombre y la naturaleza. El capitalismo conlleva intrínsecamente en su dinámica un aumento acumulativo de la destructividad que tendencialmente lleva a la catástrofe del sistema entero: "no solamente analiza la destructividad del mercado en relación a su produclividad, sino que llega al resultado de que esla destruclividad aumenta más rápidamente que la propia productividad. El sistema se transforma en un peligro para la misma sobrevivencia de la humanidad" (Hinkelammert, 1991a, p. 13).

Ellacuría habla de la "malicia intrínseca" del capitalismo por su tendencia explotadora y depredatoria que lleva a un "arrastre casi irresistible hacia una profunda deshumanización, inserta intrínsecamente en los dinamismos reales del sislema capitalista: modos abusivos y/o superficiales y alienantes de buscar la propia seguridad y felicidad por la vía de la acumulación privada, del consumismo y del entretenimiento; sometimiento a las leyes del mercado consumista, promovido propagandísticamente en todo tipo de actividades, incluso en el terreno cultural; insolidaridad manifiesta del individuo, de la familia, del Estado en contra de otros individuos, familias o Estados... la ferocidad depredatoria se convierte en el dinamismo fundamental y la solidaridad generosa se queda reducida a sanar incidental y superficialmente las heridas de los pobres, que causó la depredación" (1992, p. 405). De ello Ellacuría concluye que el ideal práctico de la civilización del capital no es universalizable materialmente ni deseable desde el punto de vista ético: "el estilo de vida propuesto en y por mecánica de su desarrollo no humaniza, plenifica ni hace feliz, como lo demuestra, entre otros índices, el creciente consumo de drogas, constituido en uno de los principales problemas del mundo desartollado. Ese estilo de vida está movido por el miedo y la inseguridad, por la vaciedad interior, por la necesidad de dominar para no ser dominado, por la urgencia de exhibir lo que se tiene, ya que no se puede comunicar lo que se es" (ibídem, p. 407).

3. El mercado es el único ordenamiento económico racional. Los teóricos neoliberales sostienen que el mercado es un sistema autorregulado porque existe una tendencia al equilibrio en el libre juego de sus factores. Sin embargo, ésta no es una afirmación empírica, sino dogmática que afirma que la tendencia al equilibrio se producirá más en tanto y en cuanto más se asegure la libertad de contrato en todos los mercados y en todas las actividades (Hinkelammert, 1984, pp. 60-62). La competencia perfecta no es un concepto empírico sino un concepto 
límite trascendental y en ningún caso hay una tendencia automática de aproximación al concepto límite (ibidem). El mismo Hayek reconoce que la "competencia perfecta significa realmente la falta total de actividades competitivas". La competencia realmente existente no puede producir una tendencia al equilibrio, justamente porque el equilibrio perfecto es lo opuesto a la competencia; la competencia implica el desequilibrio (ibídem). En ningún caso hay automatismos que produzcan tendencias empíricas a conceptos límites. Sostener su existencia presupone confundir conceptos empíricos y conceptos trascendentales. Históricamente, nunca ha existido un mercado competitivo en las diferentes fases de desartollo del capitalismo (Lechner, 1981). La idea de un mercado autorregulador es una utopía, pero los neoliberales no sienten el carácter utópico de esa utopía. Conciben el mercado como la presencia de una perfección que hace falta imponer, y por ello propugnan una extensión agresiva del mercado y la destrucción o debilitamiento de todos los grupos que puedan poner resistencia a la política del mercado total (Hinkelammert, 1987, p. 192).

4. El neoliberalismo no significa una desestatización de la vida social, como lo afirman sus ideólogos, sino una reestructuración de los fines del Estado por la cual se minimizan las funciones sociales y se fortalecen las coercitivas, con el objeto de fortalecerse frente a la sociedad civil y sus demandas. Su proyecto es de un Estado vanguardista que debe extender y profundizar la lógica del mercado e imponer su antiintervencionismo (Vergara, 1983, p. 24). Su crítica a la organización burocrática del Estado no busca una mayor participación de las masas ni una real democratización, sino el "derrocamiento de la política" (Hayek) como forma de autodeterminación colectiva de los medios de vida y la eliminación de todos los grupos sociales que puedan oponerse al ordenamiento capitalista (ibídem, p. 233; Crozier, 1989, pp. 71-80). En este sentido, su rechazo a la justicia social o distributiva y la afirmación total del mercado se dirige a la vez contra la racionalidad material de las masas y su participación política, que les permita transformar sus condiciones de vida. El capitalismo es reacio a toda forma de racionalidad material porque le presenta problemas de legitimación (Lechner, 1986, p. 234).

La concepción neoliberal del Estado como instrumento en función del beneficio imputado a la libertad económica se fundamenta en un individualismo radical que atomiza a la sociedad al grado de perder toda referencia a la totalidad. La sociedad es reducida a un conjunto de unidades claramente delimitadas y establecidas, cuyas relaciones pueden ser clasificadas según reglas unívocas (Lechner, 1981, p. 27). La consecuencia de esto es una concepción negativa del poder que siempre se considera como coerción ilegítima que amenaza la libertad individual o la restringe. Su individualismo metodológico les bloquea pensarlo como relación social y analizar las relaciones de dominación que son de índole preponderantemente estructural. Polanyi muestra que históricamente el intervencionismo estatal sobre el mercado se configuró como una reacción 
espontánea, una defensa colectiva por medio del Estado, contra la disgregación social y por el fracaso de la libertad prometida por el mercado. Fue la total mercantilización de la vida humana lo que engendró la necesidad de restringir el mercado (ibidem). Por ello, en el debate sobre Estado y mercado, hay que repensar la Razón del Estado, no en el sentido clásico de una "lógica" propia del poder, sino como categoría histórica que simboliza la totalidad social. Si lo característico de la sociedad capitalista es la organización de todas las relaciones sociales en tomo a la economía de mercado - y el fracaso de ésta como eje articulador- se hace necesario otro principio organizador basado en la Razón de Estado (intervencionismo estatal) que asegure la reproducción de la vida social (ibidem, p. 31).

5. La democracia es sólo un método político y debe adecuarse al orden de las tradiciones y normas sociales (Jaraquemada, 1991, pp. 41-52). Se elimina toda referencia ética y se propone un concepto de democracia que refleja lo que son los individuos dentro de la sociedad de mercado y de cómo se comporta efectivamente el sistema político en las sociedades capitalistas desarrolladas (Bachrach, 1973). La democracia es un mecanismo para elegir y autorizar gobiernos a través de la competencia entre dos o más grupos de élites, organizados en partidos políticos. Se rechaza el concepto de democracia de la teoría liberal clásica y su contenido ético y se sustituye por un modelo basado en la competencia mutua entre élites políticas y donde el papel de los ciudadanos se reduce a la mera elección periódica de sus gobemantes (ibídem). Es un concepto abstracto de democracia, opuesto al del liberalismo democrático y de toda forma de socialismo, del que se excluye la dimensión social, económica y toda propuesta de democratización real de la sociedad y del Estado. La democracia no asume categorías valorativas, "la democracia no suministra más que una armazón dentro de la cual los ciudadanos pueden actuar de una manera más o menos organizada y coherente" (Popper, 1967, p. 420). En esta línea, Hayek afirma que "la democracia no entraña un valor último o absoluto y ha de ser juzgada por sus logros. Probablemente la democracia es el método para conseguir ciertos fines, pero no constituye un fin en sí misma" (1975, p. 146). Esto implica que la democracia puede ser sustituible por el autoritarismo cuando su funcionamiento vaya contra la lógica del mercado. Desde aquí se entiende la paradoja de la libertad o de la tolerancia que plantea Popper: no podemos ser ilimitadamente tolerantes con los intolerantes: "La tolerancia ilimitada debe conducir a la desaparición de la tolerancia. Si extendemos la tolerancia ilimitada aun a aquellos que son intolerantes, si no nos hallamos preparados para defender una sociedad tolerante contra las tropelías de los intolerantes, el resultado será la destrucción de los tolerantes, $y$, junto con ellos, de la tolerancia" (citado por Jaraquemada, 1991, p. 48). La democracia, por tanto, desde la visión neoliberal, no puede definirse como el gobiemo de la mayoría, por cuanto si bien las elecciones tienen importancia para determinar qué élites van a gobernar, hay que cuidar que 
la mayoría resultante de la aplicación del método no gobieme tiránicamente (Popper, 1988). Popper critica la teoría clásica de la democracia por haber colocado el centro de la cuestión política en la pregunta " ¿Quién debe gobemar el Estado?", y de la cual deriva, según él, la tesis de la soberanía popular incontrolada. La pregunta central debe ser: ¿Cómo evitar las situaciones en que un mal gobernante puede causar graves daños?". La visión neoliberal de la democracia, prioriza, por tanto, el control institucional y la gobemabilidad sobre la soberanía y participación de las masas.

6. Los neoliberales sustituyen la soberanía popular por la concepción de la soberania de la ley, identificando la democracia y el liberalismo político con este principio. El Estado de Derecho "significa que el Estado está sometido en todas sus acciones a normas fijas y conocidas de antemano; normas que permiten a cada uno prever con suficiente cerlidumbre cómo usará la autoridad en cada circunstancia sus poderes coercitivos, y disponer los propios asuntos individuales sobre la base de ese conocimiento" (Hayek, 1985, p. 102). El derecho en la concepción neoliberal no debe ir en contra de la moral tradicional de la sociedad y debe operar como una salvaguardia del ámbito privado frente al intervencionismo del Estado y a la expansión de los límites del ejercicio del poder (Hayek, 1975, p. 286). El derecho debe estar ajustado al orden espontáneo del mercado y sus normas deben corresponder a lo que Popper llama "leyes sociológicas o leyes naturales de la vida social", que son inmulables (Jaraquemada, o.c., p. 52).

En definitiva, el funcionamiento de la sociedad debe supeditarse a un marco jurídico, general y permanente, basado en las tradiciones y orientado a la competencia económica. El valor de la tradición que exaltan los neoliberales implica una fuerte limitación al principio de la soberanía popular. Una mayoría circunstancial no puede derogar lo que se considera conforma el perfil más básico de una sociedad y que se fundamenta en sus tradiciones, sobre todo la del mercado:

Normalmente un grupo de hombres no se convierte en sociedad porque se dé leyes a sí mismo, sino por obedecer idénticas normas de conducta. Esto último significa que el poder de la mayoría viene limitado por estos principios comúnmente mantenidos y que no existe poder legítimo fuera de los mismos (Hayek, 1975, p. 147).

Para realizar este Estado de Derecho, Hayek propone una "utopía liberal" en la cual todas las facultades legislativas estarían concentradas en una cámara de representantes elegido exclusivamente entre las personas exitosas en el mercado (Vergara, 1991, p. 111). Popper propone una democracia restringida basada en un sistema bipartidista que elimine la representación proporcional (1988, pp. 14-15). Nozick apuesta a una idea "minianarquista" de Estado, donde éste sea sólo protector y que no tenga derecho a imponer contribuciones. 
Se trata de un Estado mínimo que sea compatible con la libertad y que no coarte los derechos individuales naturales (Merquior, 1993, p. 186).

\section{Conclusión}

Hemos analizado crílicamente algunos principios del paradigma neoliberal, sin asumir a priori un modelo que se considere adecuado. No hemos hecho referencia a modelos o coordenadas intelectuales absolutas. Analizamos el neoliberalismo de acuerdo con su propio paradigma y a partir de las inconsistencias e incompatibilidades entre la teoría neoliberal y ciertos supuestos pertenecientes a la tradición del pensamiento crítico. Entre estos supuestos están los siguientes:

1. El principio de la vida: todos los seres humanos tienen derecho a ella y no se puede sacrificar la vida de otros para afirmar la lógica del mercado.

2. La opción preferencial de los pobres: la lucha por la cultura de la vida tiene como referente privilegiado la vida de los pobres, de las mayorías populares.

3. El desarrollo de la personalidad: todos los seres humanos deberían tener las condiciones sociales, económicas y culturales para desarrollar sus capacidades y potencialidades. Si una racionalidad económica o política lo impide no es humana ni ética.

4. La democracia como autodeterminación colectiva de los medios de vida de la sociedad, lo cual implica una sociedad civil fuerte, abierta, libre y plural sobre la base de relaciones de solidaridad que trasciendan la pura agregación de intereses privados.

5. El ser humano no se reduce a su dimensión económica en el mercado.

6. Es dificil imaginar una sociedad carente de relaciones de solidaridad.

7. La complejidad, heterogeneidad y diferenciación socioeconómica y cultural de las sociedades latinoamericanas, hace muy dificil concebirlas como un sistema de tradiciones que tienen en el mercado su núcleo central.

8. Los sistemas capitalistas en América Latina han sido incapaces de satisfacer las necesidades básicas de la mayor parte de la población, han creado desigualdades cada vez mayores, han llevado a una enorme deuda externa, han producido con frecuencia crisis económicas profundas y han promovido una cultura inmoral del consumismo y de la ganancia fácil.

Con esta exposición hemos tratado de contribuir a la recuperación del pensamiento crítico a partir de una crítica a la ideología neoliberal, que hoy se presenta con caracteres hegemónicos. No se trata de reivindicar un pensamiento utópico, ideologizado y subjetivo, sino tratar de romper con el estrechamiento radical de los límites de lo que aparece como posible. La política neoliberal en 
América Latina ha tenido éxito en encarcelar el imaginario colectivo, cerrando los límites de lo que es siquiera imaginable como posible (Lander, 1991, p. 163). Ello hace necesario recuperar el pensamiento crítico, de reivindicar que las cosas pueden ser de otra manera. La idea del fin de la historia, el universalismo tecnocrático neoliberal implican la imposición de un sólo modelo de vida posible; negando, a nombre del pragmatismo y del fin de las utopías, toda posibilidad alternativa. Sin un referente utópico alternativo, no hay desde dónde imaginar que lo dado no es lo único posible. La utopía como horizonte utópico, como lo imposible que orienta lo posible y lo posible que manifiesta el potencial reprimido de la existente dimensión sin la cual no hay un pensamiento crítico.

\section{Referencias bibliografícas}

Bachrach, P., Crítica de la Teoría Elitista de Democracia, Amorrortu, Buenos Aires, 1973.

Bedoy, Humberlo, "Proycclo Sociocconómico Neoliberal", en Neoliberales y Pobres, CINEP, Santafé dc Bogotá, 1993, pp. 123-151.

Bell, Daniel, El Fin de las Ideologlas, Madrid, España, Ministerio de Trabajo, Seguridad Social, 1992.

Crozier, Michel, “ ¿Hacia dónde debc dirigirse hoy la política?”, Revista Ciencia Polffica, No. 14, ler Trimestre, Colombia, 1989.

De Sebastián, Luis, "El Neoliberalismo una Negación del Liberalismo", Revisla Realidad Económico-Social, No. 11, scptiembre-octubre, San Salvador, 1989.

De Sebastián, Luis, "El Neoliberalismo. Argumentos a favor y en conlra", en varios, El Neoliberalismo en Cuestión, Santander: Ed. Sal terrac, España, 1993.

Ellacuría, Ignacio, "En torno al coneepto y a la idea de liberación", en Implicaciones Sociales y Poltticas de la Teología de la Liberación, Escucla de Estudios Hispanoamericanos, Instiluto de Filosofía, Madrid, 1985.

Ellacuría, Ignacio, Filosoffa de la Realidad Histórica, San Salvador: UCA Editores, 1990.

Ellacuría, Ignacio, Veinte Años de Historia en El Salvador (Escritos Polticicos), 3 Tomos, San Salvador: UCA Editores, 1991.

Ellacuría, Ignacio, "Utopía y Profetismo", en Mysterium Liberationis. Conceptos Fundamentales de la Teología de la Liberación, San Salvador: UCA Editores, 1992, pp. 393-442.

Fernández, David, "El Aclual Escenario Internacional", cn Varios, Neoliberales y Pobres. EI Debate Continental por la Justicia, CINEP, Santafé de Bogolá, Colombia, 1993.

Friedman, Milton y Friedman, Rosc D., "Tres Etapas Básicas del Pensamiento Político Occidental", Revista Ciencia Políitica, No. 17, IV Trimestre, Colombia, 1989.

Fukuyama, F., "The End of History", en The National lnterest, 1989.

Gómez, E., "Reflexiones sobre el Neoliberalismo", Revista Ciencia Polftica, No. 15, II Trimestre, Colombia, 1989.

Hayek, Camino de Servidumbre, Madrid: Editorial Alianza, 1985.

Hayek, Friedrich, Los fundamentos de la liberıad, Madrid: Unión Editorial, 1975.

Hinkelammert, Franz, Ideologias del desarrollo y dialéctica de la historia, Ed. Nueva Universidad, Universidad Católica de Chile, Buenos Aires: Ed. Paidos, 1970. 
Se trata de un Estado mínimo que sea compatible con la libertad y que no coarte los derechos individuales naturales (Merquior, 1993, p. 186).

\section{Conclusión}

Hemos analizado críticamente algunos principios del paradigma neoliberal, sin asumir a priori un modelo que se considere adecuado. No hemos hecho referencia a modelos o coordenadas intelectuales absolutas. Analizamos el neoliberalismo de acuerdo con su propio paradigma y a partir de las inconsistencias e incompatibilidades entre la teoría neoliberal y ciertos supuestos pertenecientes a la tradición del pensamiento crítico. Entre estos supuestos están los siguientes:

1. El principio de la vida: todos los seres humanos tienen derecho a ella y no se puede sacrificar la vida de otros para afirmar la lógica del mercado.

2. La opción preferencial de los pobres: la lucha por la cultura de la vida tiene como referente privilegiado la vida de los pobres, de las mayorías populares.

3. El desarrollo de la personalidad: todos los seres humanos deberían tener las condiciones sociales, económicas y culturales para desarrollar sus capacidades y potencialidades. Si una racionalidad económica o política lo impide no es humana ni ética.

4. La democracia como autodeterminación colectiva de los medios de vida de la sociedad, lo cual implica una sociedad civil fuerte, abierta, libre y plural sobre la base de relaciones de solidaridad que trasciendan la pura agregación de intereses privados.

5. El ser humano no se reduce a su dimensión económica en el mercado.

6. Es difícil imaginar una sociedad carente de relaciones de solidaridad.

7. La complejidad, heterogeneidad y diferenciación socioeconómica y cultural de las sociedades latinoamericanas, hace muy difícil concebirlas como un sistema de tradiciones que tienen en el mercado su núcleo central.

8. Los sistemas capitalistas en América Latina han sido incapaces de satisfacer las necesidades básicas de la mayor parte de la población, han creado desigualdades cada vez mayores, han llevado a una enorme deuda externa, han producido con frecuencia crisis económicas profundas y han promovido una cultura inmoral del consumismo y de la ganancia fácil.

Con esta exposición hemos tratado de contribuir a la recuperación del pensamiento crítico a partir de una crítica a la ideología neoliberal, que hoy se presenta con caracteres hegemónicos. No se trata de reivindicar un pensamiento utópico, ideologizado y subjetivo, sino tratar de romper con el estrechamiento radical de los límites de lo que aparece como posible. La política neoliberal en 
América Latina ha tenido éxito en encarcelar el imaginario colectivo, cerrando los límites de lo que es siquiera imaginable como posible (Lander, 1991, p. 163). Ello hace necesario recuperar el pensamiento crítico, de reivindicar que las cosas pueden ser de otra manera. La idea del fin de la historia, el universalismo tecnocrático neoliberal implican la imposición de un sólo modelo de vida posible; negando, a nombre del pragmatismo y del fin de las utopías, toda posibilidad alternativa. Sin un referente utópico alternativo, no hay desde dónde imaginar que lo dado no es lo único posible. La utopía como horizonte utópico, como lo imposible que orienta lo posible y lo posible que manifiesta el potencial reprimido de la existente dimensión sin la cual no hay un pensamiento crítico.

\section{Referencias bibliografícas}

Bachrach, P., Crifica de la Teoría Elitista de Democracia, Amorrortu, Buenos Aires, 1973.

Bedoy, Humberto, "Proyeclo Sociocconómico Neoliberal", en Neoliberales y Pobres, CINEP, Santafé de Bogotá, 1993, pp. 123-151.

Bell, Daniel, El Fin de las Ideologlas, Madrid, España, Ministerio de Trabajo, Seguridad Social, 1992

Crozier, Michel, “'Hacia dónde debe dirigirse hoy la política?”, Revisła Ciencia Política, No. 14, ler Trimestre, Colombia, 1989.

De Sebastián, Luis, "El Neoliberalismo una Negación del Liberalismo", Revista Realidad Económico-Social, No. 11, scpticmbre-octubre, San Salvador, 1989.

De Sebastián, Luis, "El Neoliberalismo. Argumentos a favor y en contra", en varios, El Neoliberalismo en Cuestion, Santander: Ed. Sal terrae, España, 1993.

Ellacuria, lgnacio, "En torno al concepto y a la idea de liberación", en Implicaciones Sociales y Políticas de la Teología de la Liberación, Escuela de Estudios Hispanoamericanos, Instituto de Filosofía, Madrid, 1985.

Ellacuría, Ignacio, Filosofia de la Realidad Histórica, San Salvador: UCA Editores, 1990.

Ellacuría, Ignacio, Veinte Años de Historia en El Salvador (Escritos Politicos), 3 Tomos, San Salvador: UCA Editores, 1991.

Ellacuría, Ignacio, "Utopía y Profetismo", en Mysterium Liberationis. Concepros Fundamentales de la Teología de la Liberación, San Salvador: UCA Edilores, 1992, pp. 393-442.

Fernández, David, "El Actual Escenario Internacional", en Varios, Neoliberales y Pobres. El Debate Continental por la Justicia, CINEP, Santafé de Bogotá, Colombia, 1993.

Friedman, Milton y Friedman, Rose D., "Tres Elapas Básicas del Pensamiento Político Occidental", Revista Ciencia Política, No. 17, IV Trimestrc, Colombia, 1989.

Fukuyama, F., "The End of History", cn The National Interest, 1989.

G6mez, E., "Reflexiones sobre el Neolibcralismo", Revista Ciencia Politica, No. 15, II Trimestre, Colombia, 1989.

Hayek, Camino de Servidumbre, Madrid: Editorial Alianza, 1985.

Hayek, Friedrich, Los fundamentos de la libertad, Madrid: Unión Editorial, 1975.

Hinkelammert, Franz, Ideologías del desarrollo y dialéctica de la hisioria, Ed. Nueva Universidad, Universidad Católica de Chile, Bucnos Aires: Ed. Paidos, 1970. 
Hinkelammer, Franz, Las armas ideologicas de la muerte, EDUCA, San José, Costa Rica, 1977.

Hinkelammen, Franz, Crítica de la Razón Uiópica, San José: Ed. DEI, Costa Rica, 1984.

Hinkelammert, Franz, Democracia y Totalitarismo, San José: Ed. DEI, Costa Rica, 1987.

Hinkelammert, Franz, "El papel regulador del Estado y los problemas de la autorregulación del Mercado", Revista Pasos, No. 33, Departamento Ecuménico de Investigaciones (DEI), San José, Costa Rica, $1991 a$.

Hinkelammert, Franz, Sacrificios Humanos y Sociedad Occidental, San José: Ed. DEI, Costa Rica, 19916.

Jaraquemada Roblero, Jorge A., "Los Límiles de la Democracia en el Neoliberalismo", Revisia Ciencia Politica, No. 22, II Trimestre, Colombia, 1991.

Jaramillo, Mario, "Cincuenta Puntos Claves Sobre Capitalismo y Socialismo", Revista Ciencia Polttica, No. 14, 1er. Trimestre, Colombia, 1989.

Kuhn, Thomas, La Estructura de las Revoluciones Cientificas, FCE, México, 1971.

Lander, Edgardo, "Retos del Pensamiento Crítico Latinoamericano en la Década de los Noventa", en Edgardo Lander (ed), Modernidad y Universalismo, Caracas: Editorial Nueva Sociedad, Venezuela, 1971, pp. 145-177.

Lechner, Norbert, "Acerca de la Razón del Estado", Material de Discusión, No. 15, Programa FLACSO, Santiago de Chilc, 1991.

Lechner, Norbert, "El Proyecto Neoconservador y la Democracia" en Julio Labastida y Martín del Campo, Los Nuevos Procesos Sociales y la Teoría Polifica Consemporánea, Siglo XXI Editoriales, México, 1986.

Lechner, Norbert, "Un desencanto llamado postmodernismo", documento de trabajo, No. 369, programa FLACSO, Santiago de Chile, 1988.

Lópcz Camps, Jordi, "Diálogos para un amigo neoliberal", en Varios, El Neoliberalismo en Cuestion, Santander: Edit. Sal terrae, España, 1993.

Macpherson, C.B., La Realidad Democrótica, Barcelona: Ed. Fontanella, 1968.

Macpherson, Crawford, La teoría Política del Individualismo Posesivo, Barcelona: Ed. Fontanella, 1970.

Mardones, José María y Aguirre, Rafael, El Hombre y la sociedad de Consumo ante el Juicio del Evangelio, Bilbao: Editorial Sal Terrae, 1989.

Mardones, José María, "Razón Económica Capilalista y Teología Política Neoconservadora", en Varios, El Neoliberalismo en Cuestión, Santander: Edit. Sal terrae, España, 1993.

Mairet, G., "El Liberalismo: Presupuestos y Justificaciones"; en F. Chatelet, Historia de las Ideologías, Tomo 3, Premia Editores, México, 1980.

Mera, Jorge, "Neoliberalismo y Derechos Humanos", Seminario "El Neoliberalismo y la Experiencia Chilena", auspiciado por la Academia de Humanismo Cristiano y CLACSO, marzo, Santiago de Chile, 1983.

Merquior, José Guilherme, "Una panorámica del Renacimiento de los Liberalismos", Revisfa Ciencia Politica, No. 12, Tercer Trimestre, Colombia, 1988.

Merquior, Jose Guilherme, Liberalismo Viejo y Nuevo, Fondo de Cultura Económica, México, 1993.

Millas, Jorge, "La Concepción de la Libertad de Poder de Friedrich Von Hayek", mimeo, Seminario "El Neoliberalismo y la Experiencia Chilena", auspiciado por la Academia de Humanismo Cristiano y CLACSO, marzo, Santiago de Chile, 1983.

Mo Sung, Jung, Neoliberalismo y Pobreza, San José: Ed. DEI, Costa Rica, 1993. 
Popper, Karl, El Desarrollo del Conocimiento Cientifico, Conjeturas y Refutaciones, Bucnos aires: Ed. Paidós, 1967.

Popper, Karl, La Miserio del Historicismo, Madrid: Alianza Editorial, 1973.

Popper, Karl, "Un Repaso de mi Teoría de la Democracia", Revista Vuelıo, 143, octubre, México, 1988.

Popper, Karl, "Tesis sobre los principios liberales", Revista Ciencia Políica, No. 17, IV Trimestre, Colombia, 1989.

Samour, Héctor, Democracia, Liberalismo y derechos Humanos, Instituto de Derechos Humanos, UCA, San Salvador, 1987.

Tezanos, José Félix, "La crítica de la razón cconómica y la razón de la crítica social", en Revista El Socialismo del Futuro, No. 3, Fundación Sisıema, Madrid, España, 1991.

Trigo, Pcdro, "El mundo como mercado. Significado y juicio", en varios, El Neoliberalismo en cuestion, Santander: Editorial Sal Icrrac, 1993, pp. 303-319.

Vargas Llosa, Mario, "Karl Popper al Día”, Revisıa Vuelia, No. 184, marzo, México, 1992.

Vergara, Jorge, "La Crílica Neoliberal a la Democracia", mimco, Seminario "El Neoliberalismo y la Experiencia Chilena", auspiciado por la Academia de Humanismo Cristiano y CLACSO, marzo, Santiago de Chile, 1983.

Vergara, Jorge, "La Contribución de Popper a la Tcoría Ncoliberal", versión modificada de la contribución al IV Seminario de la Comisión de epistemología y Política de CLACSO, Críica y Uropia, No. 12, CLACSO, Buenos Aires, 1984.

Vergara, Jorge, "El Paradigma Liberal Democrático: Notas para una investigación", Sociológica, No. 7-8, Universidad Autónoma Mctropolitana, diciembre, México, 1988.

Vergara, Jorge, "Crílica Latinoamericana al Neoliberalismo: acción comunicativa y desarrollo del pensamiento crilico en América Latina, en Modernidad y Universalismo", Caracas: Edit. Nueva Socicdad, Venezucla, 1991, pp. 101-124.

Varios, Neoliberales y Pobres. El debate continental por la Justicia, Colombia, CINEP, Santafé de Bogotá, 1993. 